\title{
Genetic Selection for Reciprocal Translocation at Chosen Chromosomal Sites in Saccharomyces cerevisiae
}

\author{
SERGE POTIER, BARBARA WINSOR, AND FRANÇOIS LACROUTE* \\ Laboratoire de Génétique Physiologique, Institut de Biologie Moleculaire et Cellulaire, Centre National de la \\ Recherche Scientifique, 67084 Strasbourg Cedex, France
}

Received 21 December 1981/Accepted 14 May 1982

\begin{abstract}
We have constructed viable Saccharomyces cerevisiae strains containing a reciprocal translocation between the URA2 site of chromosome $\mathrm{X}$ and the HIS3 site of chromosome XV. Our methodology is an extension of the method originally developed to introduce an altered cloned sequence at the chromosomal location from which the parent sequence was derived (S. Scherer and R. W. Davis, Proc. Natl. Acad. Sci. U.S.A. 76:4951-4955, 1979). It comprises three essential steps. First, a nonreverting $u r a 2^{-}$strain was constructed by deleting a 3.7-kilobase fragment from the coding sequence of the wild-type URA2 gene. Second, part of the coding sequence of the wild-type URA2 gene (without promotor) was inserted at the HIS3 locus of the $u r a 2^{-}$strain. Third, after several generations of growth on uracil-supplemented medium, $\mathrm{ura2}^{+}$colonies were selected which resulted from mitotic recombination between the nonoverlapping deletions of $U R A 2$ located on chromosomes $\mathrm{X}$ and $\mathrm{XV}$.
\end{abstract}

In 1980, Chaleff and Fink (2) and Roeder and Fink (13) described reciprocal translocation between chromosomes I and III and chromosomes III and XII. These translocations are very likely the products of illegitimate recombination between the insertion element Ty1 (1) and nonhomologous DNA on another chromosome.

We have developed a method involving reciprocal translocation between two chosen chromosomal sites, URA2 on chromosome $\mathrm{X}$ and $H I S 3$ on chromosome $\mathrm{XV}$, genetically selected for recombination between nonoverlapping deletions of URA2. This method is an extension of the one originally developed to reinsert altered cloned sequences at their chromosomal location (14). As starting material, we needed an unexpressed sequence of one of the genes which could be integrated at the other selective marker locus without changing the auxotrophic phenotype of the receptor strain. The URA2 (7) gene was chosen because a 6.4-kilobase (kb) BamHI fragment containing coding sequences for its enzymes, that is, part of the carbamyl phosphate synthetase sequence and the aspartate transcarbamylase sequence (but not their promoter), had been cloned recently and its restriction map was described (J. L. Souciet, J. C. Hubert, and F. Lacroute, Mol. Gen. Genet., in press). HIS3, the structural gene for imidazoleglycerolphosphate dehydratase, was used as the selective marker and is completely enclosed in a 1.7kb BamHI fragment (gift of A. Hinnen, originally from J. D. Friesen).
In this paper we present the different detailed steps of the method as well as genetic and biochemical evidence that allowed us to demonstrate the occurrence of the reciprocal translocation.

\section{MATERIALS AND METHODS}

Yeasts, bacteria, and plasmids. Saccharomyces cerevisiae strains used in this study were derivatives of $\alpha$ GRF18 (his3 $3^{-}$leu2 ${ }^{-}$) (from G. R. Fink), a FL100, and $\alpha$ FL200. They were grown in YEPD (1\% yeast extract, $2 \%$ peptone, $2 \%$ glucose) or in YNB (yeast nitrogen base [Difco], 6.7 g/iter; $2 \%$ glucose), supplemented adequately. Escherichia coli strains were grown on L-broth or minimal medium M9 (8). Ampicillin and other supplements as required were added at 50 $\mu \mathrm{g} / \mathrm{ml}$ (final concentration) in $S$. cerevisiae or $E$. coli media.

Plasmid JLS1 $\left(\mathrm{Amp}^{\mathrm{r}}\right.$, Ura2A $\left.{ }^{+}\right)$contains URA2 gene coding sequences, most of the carbamyl phosphate synthetase sequence, and all of the aspartate transcarbamylase sequence without their promoter in a 6.4-kb BamHI fragment cloned in the BamHI site of pBR322 (Souciet et al., in press). It complements the corresponding $E$. coli auxotroph MB1131 pyrB derived from DB6272 (from D. Botstein) and is deficient in aspartate transcarbamylase. The plasmids pBW2, pBW3, and pBW4 contain pJLS1 DNA in addition to a $1.7-\mathrm{kb}$ BamHI fragment containing the HIS3 gene in three of the four possible positions as presented in Fig. 1. We have determined $B g$ III sites to locate and orient $H I S 3$ with regard to $U R A 2$ in the plasmids. These plasmids complement the corresponding $E$. coli auxotrophs MB1131 pyrB and HISB463 (16).

DNA preparation. Preparation of plasmid DNA from $E$. coli cultures was as described by Clewell and 


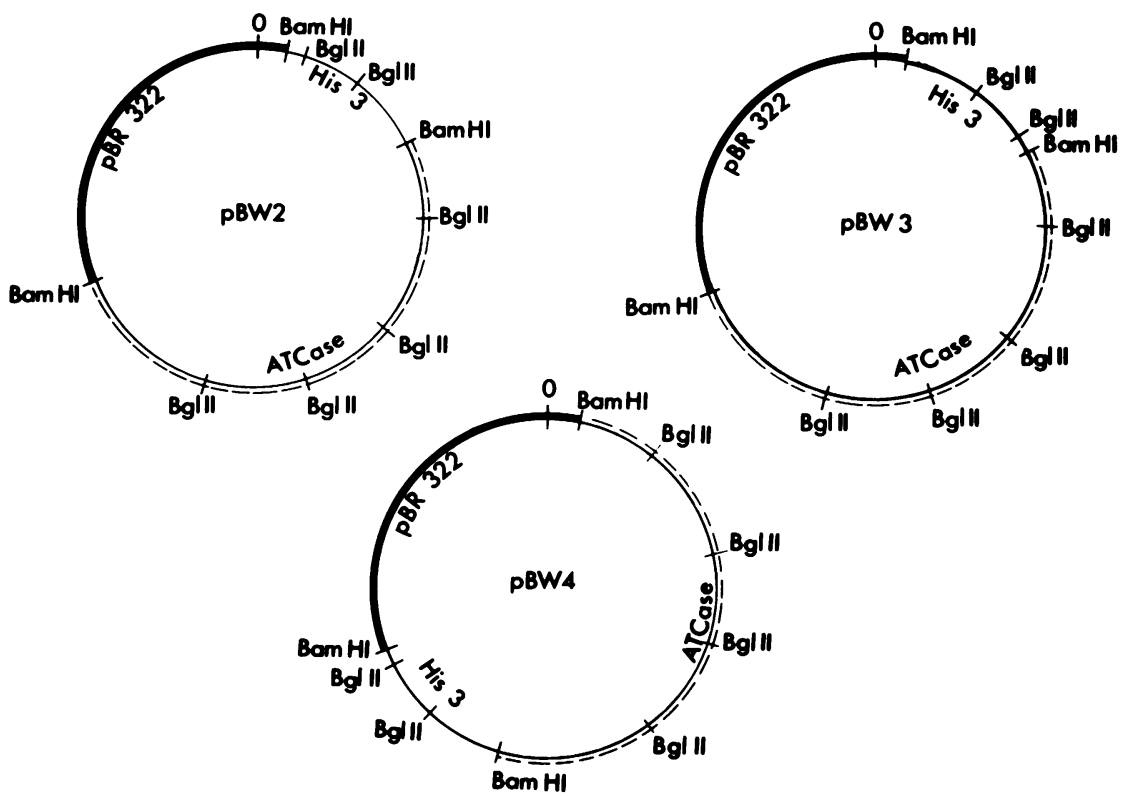

FIG. 1. Structure of plasmids pBW2, pBW3, and pBW4. The BamHI fragment of the URA2 gene is outlined by a dashed line. pBR322 is represented by a heavy solid line. The $1.7-\mathrm{kb}$ BamHI fragment containing the HIS3 gene, shown as a thin solid line, presents a slight variation compared to the results of Struhl et al. (17). We found two $B g$ III sites here, whereas the HIS3 gene from their strain contained only one BglII site.

Helinski (5) with minor modifications. We purified $S$. cerevisiae DNA by the method of Struhl et al. (18). Restriction endonuclease and ligation assays were as indicated by the suppliers (Biolabs Inc., Beverly, Mass., and Boehringer, Mannheim, West Germany). Published procedures were followed for gel electrophoresis (4), nick-translation (12), and transfer of DNA onto nitrocellulose (15).

Transformations and genetic analysis. $S$. cerevisiae cells were transformed by the method of Hinnen et al. (9). E. coli cells were transformed as described by Cohen et al. (6). $S$. cerevisiae crosses and random spore analysis were as described by Mortimer and Hawthorne (11).

Cell labeling, RNA extraction, and hybridizations. Cells were labeled with $\left[{ }^{3} \mathrm{H}\right]$ adenine, and RNA was extracted from $15-\mathrm{ml}$ cultures by the method of Waldron and Lacroute (20). Conditions for hybridization of DNA, fixed on nitrocellulose filters, to RNAs have been described elsewhere (10). We measured specific hybridization of a 1.4-kb BglII DNA fragment of the URA2 gene coding strand (called BglB) cloned in the phage M13 mp7 (J. L. Souciet and J. C. Hubert, personal communication).

\section{RESULTS}

Construction of $\alpha$ GRF18 $\triangle$ ura2A strain. Plasmid SAP101 was constructed in vitro as follows. After cleavage with $B g I I I$ and subsequent ligation, three restriction fragments totaling $3.7 \mathrm{~kb}$ were deleted from pJLS1. BglB is a part of the deletion. A BamHI fragment containing the HIS3 gene was introduced by partial restriction of this plasmid by BamHI and subsequent liga- tion. The pSAP101 structure was verified by restriction mapping and by the fact that it complemented $E$. coli HisB463 but not $E$. coli MB1131 (pyrB).

We transformed $\alpha$ GRF18 (leu2 ${ }^{-}$his $3^{-}$) with this plasmid and selected for a $\mathrm{His}^{+}$phenotype. The yeast sequences of pSAP101 could recombine with the homologous sequences on chromosome XV (HIS3) or on chromosome X (URA2). In the first case the recombinant phenotype would be $\mathrm{His}^{+} \mathrm{Ura}^{+}$; in the second case, His ${ }^{+}$ $\mathrm{Ura}^{+}$and $\mathrm{His}^{+} \mathrm{Ura}^{-}$were possible depending on the region of crossover (Fig. 2, step A). Thus, we selected for $\mathrm{His}^{+} \mathrm{Ura}^{-}$clones because this phenotype represents the only possibility for the site of integration being the URA2 locus (Fig. 2).

$\mathrm{His}^{+} \mathrm{Ura}^{-}$transformants were grown on complete medium for about $\mathbf{1 0}$ generations. After nystatin selection we looked for $\mathrm{His}^{-} \mathrm{Ura}^{-}$ strains which could have resulted from loopingout (Fig. 2, step B). In these strains we confirmed by Southern blot (Fig. 3) the presence of only the $U R A 2 A^{-}$deleted sequence; wild-type URA2A, HIS3, and pBR322 sequences must have been lost from the chromosome $\mathrm{X}$ structure. Moreover, we found $\beta$-lactamase activity resulting from pBR322 expression (3) in transformed $\alpha$ GRF18 but not in $\alpha$ GRF18 $\triangle u r a 2 A$. Finally, we did not detect any hybridization of mRNAs from $\alpha$ GRF18 $\triangle u r a 2 A$ with BglB coding-strand DNA (results not shown).

Insertion of the promoter-deleted URA2 se- 

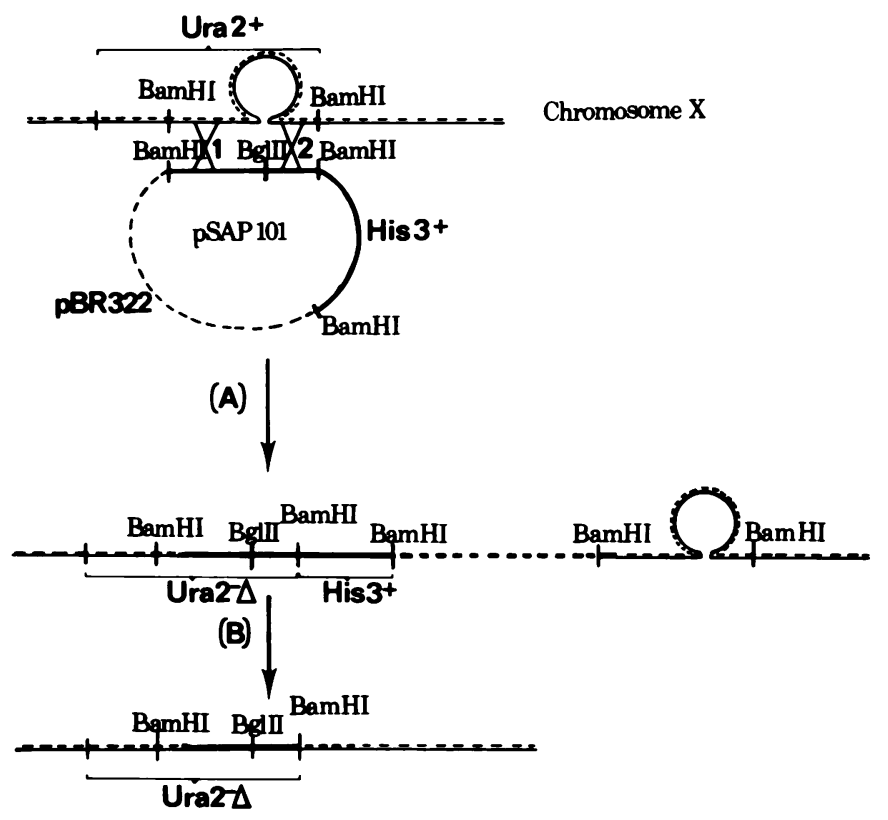

FIG. 2. Construction of a URA2A gene deletion. (A) pSAP101 introduction into $\alpha$ GRF18 chromosome X by crossover at position 1. (B) Wild-type URA2A, HIS3, and pBR322 loss (looping-out) by crossover at positions 1 and 2 .

quence into $\alpha$ GRF18 $\Delta$ ura2A. Plasmids pBW2, pBW3, and pBW4 were used to transform $\alpha$ GRF18 $\triangle u r a 2 A$ strain to insert the URA2 gene without its promoter at the HIS3 locus on chromosome XV. The transformants, called, respectively, $\alpha$ SP4, $\alpha$ SP8, and $\alpha$ SP11, were identified

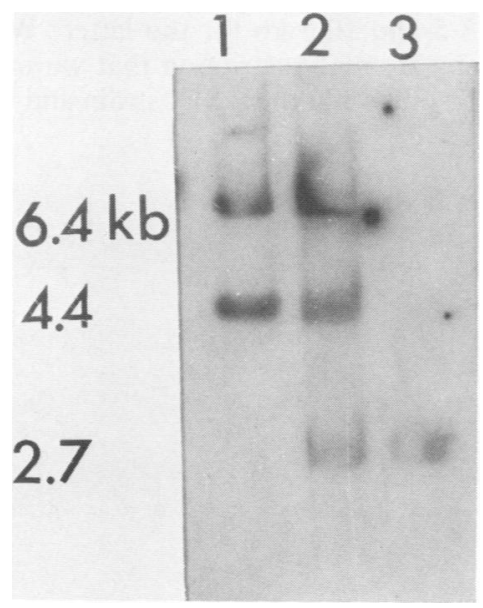

FIG. 3. Structure of strain $\alpha$ GRF18 $\Delta$ ura2A. To show that pBR322 and the URA2 sequences (of the $B a m$ HI fragment) are not present in the deleted strain, pJLS1 probe DNA was hybridized in a Southern blot with BamHI-cleaved DNA from: lane 1, pJLS1; lane 2, strain $\alpha$ GRF18 (leu2 $2^{-}$his $3^{+}$ura2 ${ }^{-}$) transformed with pBW2; lane 3, strain $\alpha$ GRF18 $\Delta$ ura2A (leu2 ${ }^{-}$his $^{-}$ ura $^{-}$). DNA sizes in $\mathrm{kb}$ are shown to the left. by crossing with a FL100 and looking for four $\mathrm{His}^{+}$spores per ascus. Their genotype was leu2 $2^{-}$his $3^{+}$ura $^{-}$. We confirmed the absence of hybridization of $\alpha$ SP4 mRNAs with BglB coding-strand DNA (results not shown).

Selection of reciprocal translocations. Translocation resulting from recombination between two fragments of the $U R A 2$ gene was selected by subjecting the $\mathrm{His}^{+}$transformants to selective pressure for a $\mathrm{Ura}^{+}$phenotype. That is, $\alpha$

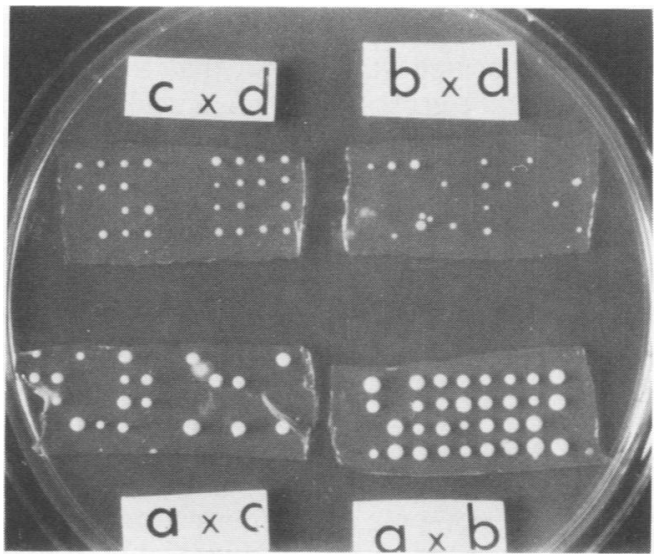

FIG. 4. Sporulation of progeny from crosses between translocated strains. Strains $\alpha$ SPT2A, a SPT2B, a SPT2C, and $\alpha$ SPT2D were abbreviated as a, $b, c$, and d, respectively. 
SP4, $\alpha$ SP8, and $\alpha$ SP11 were grown on YNB supplemented with leucine and uracil for six or seven generations, and then $5 \times 10^{6}$ cells were spread on YNB with leucine. The progeny of $\alpha$ SP8 and $\alpha$ SP11 did not give any $\mathrm{Ura}^{+}$recombinants, but $100 \mathrm{Ura}^{+}$clones were obtained from strain $\alpha \mathrm{SP} 4$, which represents a recombination frequency of $2 \times 10^{-5}$. Taking into account the different orientation of HIS3 with regard to $U R A 2 A$ in $\mathrm{pBW} 2$ as opposed to $\mathrm{pBW} 3$ and pBW4 (Fig. 1), we deduced that the translocation must have given rise to dicentromeric or acentromeric chromosomes in $\alpha$ SP8 and $\alpha$ SP11 and monocentromeric chromosomes in $\alpha$ SP4. If this is so, it could explain the preceding results regarding whether or not viable reciprocally translocated strains were obtained.

Genetic behavior of translocated strains. We have looked more closely at one of the translocated strains, called $\alpha$ SPT2 (leu2 $2^{-}$his $3^{+} u r a 2^{+}$). Strain $\alpha$ SPT2 was crossed with a FL100 to obtain a tetrad with translocated and wild-type spores of both mating types. Among 30 asci dissected, only four tetrads were found with all four spores capable of germination. These results $(4$ per 30$)$ correspond to the expected frequency of parental ditype asci. Only one tetrad contained the mating type distribution sought for: spores of $\alpha$ SPT2A, a SPT2B, a SPT2C, and $\alpha$ SPT2D. The control cross of $\alpha$ SP4 with a FL100 resulted in almost $100 \%$ germination of the dissected tetrads.

The four spores from cross $\alpha$ SPT $2 \times$ a FL100 were crossed with each other, and 12 asci per cross were analyzed (Fig. 4). Crosses a $\times b$ ( $\alpha$ SPT2A $\times$ a SPT2B) and $\mathrm{c} \times \mathrm{d}(\mathrm{a}$ SPT2C $\times \alpha$ SPT2D) gave rise to almost $100 \%$ germination, whereas crosses $\mathrm{a} \times \mathrm{c}$ and $\mathrm{b} \times \mathrm{d}$ gave rise to only $50 \%$ germination. These data suggested that $\mathrm{c} \times \mathrm{d}$ and $\mathrm{a} \times \mathrm{b}$ could be homologous crosses between two wild-type or two reciprocally translocated strains and that $\mathrm{a} \times \mathrm{c}$ and $b \times d$ could be crosses between a wild-type and a reciprocally translocated strain. The same type of results was obtained with seven other leu2his $3^{+}$ura2 $^{+}$strains.

It seemed probable at this stage that only parental type spores conserved a normal genetic complement and that recombinant genomes were not viable. To confirm this hypothesis we crossed one of the translocated strains, a SPT2C $\left(\right.$ his $^{+} \mathrm{ura2}^{+}$), with the doubly auxotrophic parental strain $\alpha$ GRF18 $\Delta u r a 2 A$, which allowed us to recognize parental and recombinant genomes by their phenotypes. After sporulation and dissection the phenotypes of the viable spores (50\%) were tested. No recombinant $\mathrm{His}^{-}$ $\mathrm{Ura}^{+}$or $\mathrm{His}^{+} \mathrm{Ura}^{-}$spores were present. To demonstrate that the $\mathrm{His}^{+} \mathrm{Ura}^{+}$spores were translocated strains and that the $\mathrm{His}^{-} \mathrm{Ura}^{-}$ spores contained the normal genetic complement, we compared the Southern blots of DNA from the two viable spores of three putative tetratypes (Fig. 5). The BamHI URA2 fragment served as a probe for the BamHI restricted DNAs. The $\mathrm{His}^{-} \mathrm{Ura}^{-}$strains SPT2E-1, SPT2F-1, and SPT2G-1 contained only one major band of $2.7 \mathrm{~kb}$, whereas the $\mathrm{His}^{+} \mathrm{Ura}^{+}$ strains SPT2E-2, SPT2F-2, and SPT2G-2 revealed two major bands of 6.4 and $2.7 \mathrm{~kb}$.

Biochemical evidence for chromosomal modifications. To obtain direct evidence for the translocation, we analyzed molecular weight differences between the chromosomal restriction patterns of $\alpha$ SP4, $\alpha$ SPT2, $\alpha$ SPT2A, a SPT2B, a SPT2C, $\alpha$ SPT2D, and $\alpha$ GRF18 $\Delta u r a 2 A$. First, we compared SalI-cleaved total DNA from each strain by using pJLS1 (Fig. 6), the BamHI URA2 fragment (Fig. 7), and pBR322 (Fig. 8) as radioactive probes. We chose $S a l$ because the $U R A 2$ BamHI fragment does not contain a SalI restriction site. Thus we could detect differences in the chromosomal neighborhood of the URA2 BamHI fragment.

The $\alpha$ SPT2A and a SPT2B strains showed only one approximately $16-\mathrm{kb}$ fragment with pJLS1 or BamHI URA2 as the probe and none with pBR322; they corresponded to the wildtype spores. The a SPT2C and $\alpha$ SPT2D strain patterns were the same as that of $\alpha$ SPT2, the parental translocated strain. The $\alpha$ SPT2 type chromosomal restriction map was significantly different from that of $\alpha$ SP4. The pJLS1 and the BamHI URA2 fragment probes revealed two bands, of about 13 and $11 \mathrm{~kb}$ for the former and about 13.5 and $10.5 \mathrm{~kb}$ for the latter. We have verified by BamHI restriction that we have the same DNA insert in the $\alpha$ SP4 strain and in the $\alpha$

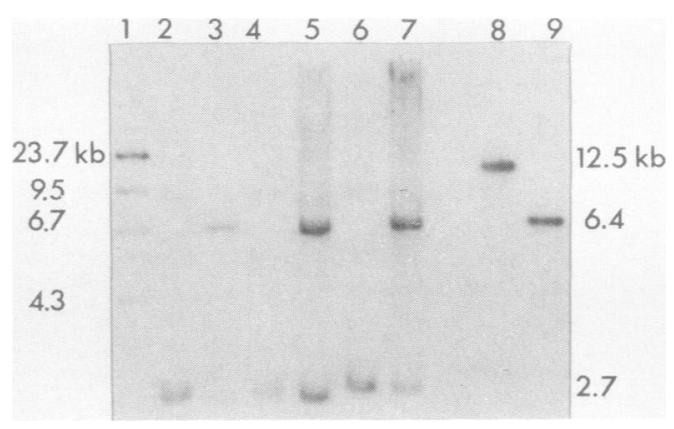

FIG. 5. URA2A content of $\mathrm{His}^{-} \mathrm{Ura}^{-}$and $\mathrm{His}^{+}$ $\mathrm{Ura}^{+}$spores. Southern blot of DNA from: lane 1 , phage $\lambda$ cleaved with HindIII; lane 2, SPT2E-1; lane 3, SPT2E-2; lane 4, SPT2F-1; lane 5, SPT2F-2; lane 6, SPT2G-1; lane 7, SPTG-2. Lane 9, pBW2 cleaved with BamHI, and lane 8, pBW2 cleaved with XhoI, after hybridization with radioactive $\lambda$ DNA and BamHI fragment DNA. 


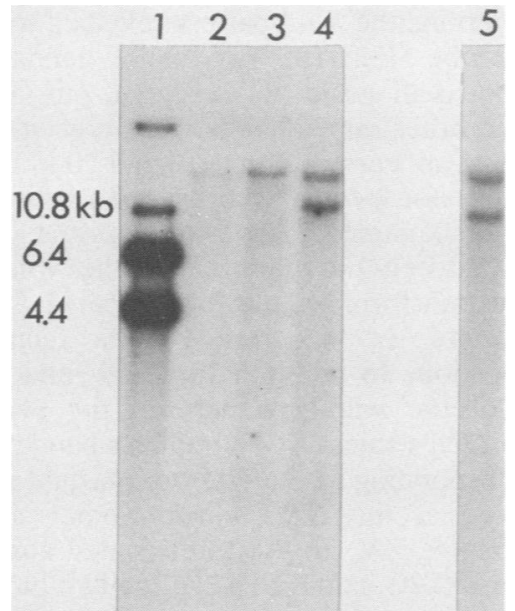

FIG. 6. URA2A and pBR322 content of translocated strains. Southern blot of DNA from (lane 1) pJLS1 cleaved with BamHI, (lane 2) $\alpha$ SPT2A, (lane 3) a SPT2B, (lane 4) a SPT2C, and (lane 5) a SP4, cleaved with Sall after hybridization with pJLS1. Sizes in kb are shown to the left.

SPT2 strain (Fig. 9). The DNA surrounding URA2 was different, however. Another translocated strain analyzed by Southern blot gave the same results (data not shown).

To demonstrate that HIS3 was translocated to chromosome X, we compared Southern blots of

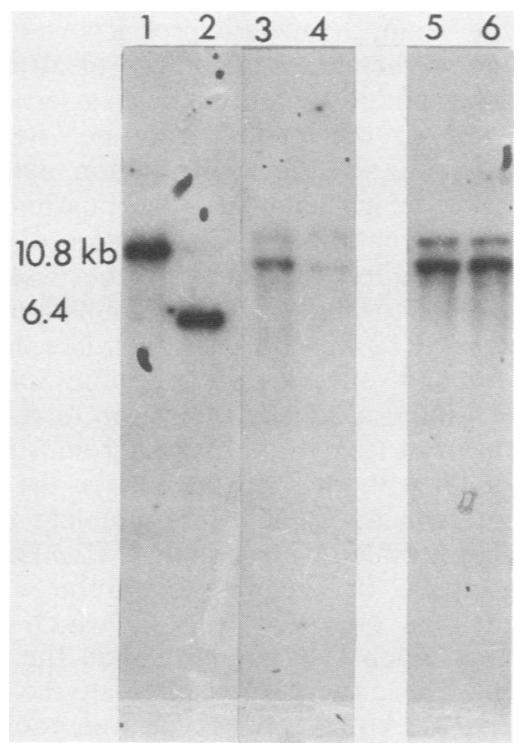

FIG. 7. URA2A content of translocated strains. Southern blot of DNA from: lane 1, pJLS1 cleaved with SalI; lane 2, pJLS1 cleaved with BamHI; lane 3, $\alpha$ SPT2; lane 4, $\alpha$ SP4; lane 5, a SPT2C; and lane 6, $\alpha$ SPT2D. All samples were cleaved with $S a l l$ after hybridization with radioactive BamHI URA2 fragment.

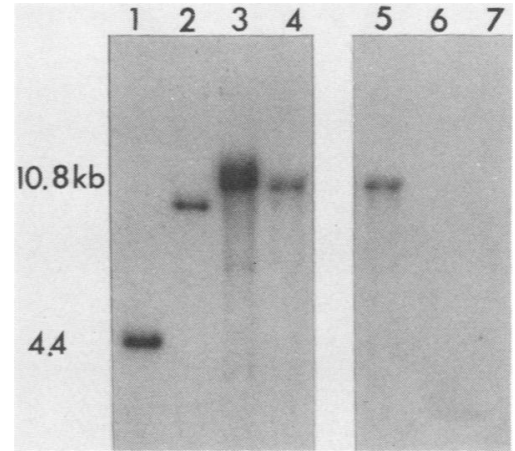

FIG. 8. pBR322 content of translocated strains. Southern blot of DNA from: lane 1, pJLS1 cleaved with BamHI; lane 2, pJLS1; lane 3, $\alpha$ SP4; lane 4, $\alpha$ SPT2D; lane 5, a SPT2C; lane 6, a SPT2B; and lane 7, a SPT2A cleaved with Sall after hybridization with radioactive $\mathrm{pBR} 322$.

XhoI-cleaved total DNA from wild-type parental and translocated strains. The HIS3 BamHI fragment $(1.7 \mathrm{~kb})$ cloned in the phage M13 $\mathrm{mp} 7$ was used as a probe (Fig. 10). There is one XhoI site in the HIS3 BamHI fragment, but none in the URA2 BamHI fragment or in pBR322.

The $\alpha$ SPT2A, a SPT2B, and $\alpha$ GRF18 $\Delta u r a 2 A$ DNAs showed four bands of about $40,20,10$, and $9 \mathrm{~kb}$. The a SPT2C, $\alpha$ SPT2D, and $\alpha$ SPT2

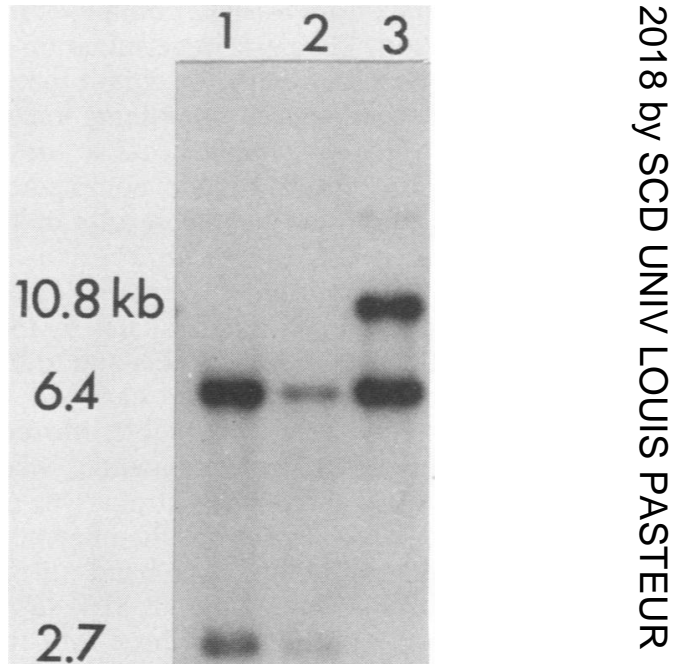

FIG. 9. URA2A content of strains $\alpha$ SP4 and $\alpha$ SPT2. (Lane 1) $\alpha$ SPT2 and (lane 2) $\alpha$ SP4 DNA cleaved with BamHI. Lane 3, Mixture of BamHIcleaved pJLS1 and Sall-cleaved pJLS1 from a Southern blot, hybridized with the BamHI URA2 fragment. 


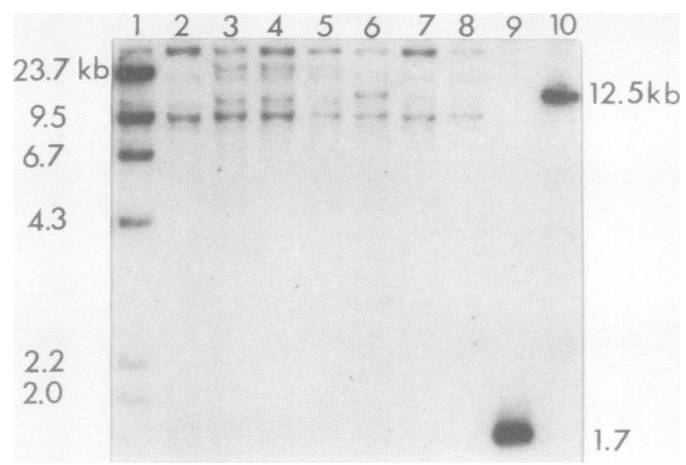

FIG. 10. HIS3 content of translocated strains. Southern blot of DNA from: lane 1 , phage $\lambda$ cleaved with HindIII; lane 2, $\alpha$ GRF18 $\triangle u r a 2 A$; lane 3, a SPT2C; lane 4, $\alpha$ SPT2D; lane 5, $\alpha$ SPT2; lane 6, $\alpha$ SP4; lane 7, $\alpha$ SPT2A; lane 8, a SPT2B. (Lane 10) pBW2 cleaved with $X$ hoI and (lane 9) pBW2 cleaved with BamHI after hybridization with radioactive probes of $\lambda$ DNA and the HIS3 BamHI fragment.

DNAs contained six bands of $40,20,10$, and 9 $\mathrm{kb}$ in addition to 25 - and $11-\mathrm{kb}$ bands. Finally, in strain $\alpha$ SP4 five bands of about $40,20,12.5,10$, and $9 \mathrm{~kb}$ were detected.

\section{DISCUSSION}

Genetic and biochemical data allow us to confirm that strain $\alpha$ SPT2 contains a reciprocal translocation. The percent germination of progeny from its cross with the wild-type a FL100 suggested that spores containing recombinant genomes were not viable because they did not conserve the entire genetic complement. This fact was confirmed by the results of the cross between a SPT2C $\left(\right.$ his $^{+}$ura2 $^{+}$) and $\alpha$ GRF18 $\triangle u r a 2 A$ (his $^{-}$ura2 ${ }^{-}$), which allowed us to follow the HIS 3 and $U R A 2$ alleles by the phenotypes of their meiotic products and to show that only parental type genomes carrying a normal genetic complement were viable. Moreover, the neighboring $U R A 2$ gene sequences were different from those in the $\alpha$ SP4 strain. One must also consider an explanation for the presence of only two URA2-containing SalI bands in Southern blots of translocated and $\alpha$ SP4 strains with pJLS1 as the probe when three SalI fragments were expected due to the Sall site in pBR322 (19). We suggest that this result is due to the superposition of two bands very close to the same size at $13 \mathrm{~kb}$, one containing the pBR322 sequences and the other containing the $\mathrm{ura2}^{-}$ deleted sequences. This is substantiated by the fact that the radioactivity visible in the $13-\mathrm{kb}$ band when only the URA2 BamHI fragment was used as the probe (Fig. 7) was less intense than that found with pJLS1 as the probe (Fig. 6).
Concerning the $X h o I$ pattern revealed with the HIS3 probe (Fig. 10), two major bands were common to all strains as expected, but in addition two other minor bands were present in all strains. It appears that the 10 - and $20-\mathrm{kb}$ bands represent nonspecific hybridization which remains unexplained. Nevertheless, the differences between the patterns of the wild-type plasmid-transformed and translocated strains substantiate the occurrence of a reciprocal translocation. In addition to the 9- and 40-kb bands of the wild-type pattern, the plasmidtransformed strain $\alpha$ SP4 contains a band of 12.5 kb corresponding to the HIS 3 of plasmid pBW2 integrated at the HIS3 chromosomal site on chromosome XV. In the translocated strains $\alpha$ SPT2, a SPT2C, and $\alpha$ SPT2D, the two bands of 11 and $25 \mathrm{~kb}$ could result from the translocation of one of the copies of the HIS3 gene to its new chromosomal location. The molecular model presented in Fig. 11 is consistent with these results.

We did not find any significant differences in the URA2 mRNA yields of FL100 and a SPT2C, $\alpha$ SPT2D, and $\alpha$ SPT2. Moreover, all these strains have the same generation time in complete as well as in minimal medium. The general behavior of the translocated strains and in particular the URA2 expression seemed to be the same even when the DNA sequences downstream from $U R A 2$ were changed.

When seven putative translocated strains were analyzed genetically by backcross to the wild-type strain, the meiotic products were nonviable at predictable percentages in all cases. Thus, other possible events such as insertions at other sites or conversion were not frequent products of our selections. In addition, evidence is available which eliminates the possibility of conversion events in the construction of the $\alpha$ SPT2 strain. First, if that were the case, one could expect to obtain $100 \%$ germination after crossing $\alpha$ SPT2 with a FL100, just like the test cross. Second, one would expect the SalI pattern by Southern blot hybridization to reveal a fragment of at least $16 \mathrm{~kb}$ from chromosome $X$ (see Fig. 11) with the same intensity as the 11-kb fragment (which contains the complete URA2 sequence) revealed with the $U R A 2 B a m H I$ fragment as probe. In fact, with this probe, a 13-kb fragment was observed (Fig. 7) which in all cases was much less intensive than the $11-\mathrm{kb}$ fragment. These two results eliminate the possibility that the Ura2 ${ }^{+}$phenotype was conferred by genetically converting the URA2 allele on chromosome $\mathrm{X}$ by the $U R A 2$ allele on chromosome XV.

This method can be applied to select reciprocal translocation between any parts of chromosomes from which DNA fragments have been 


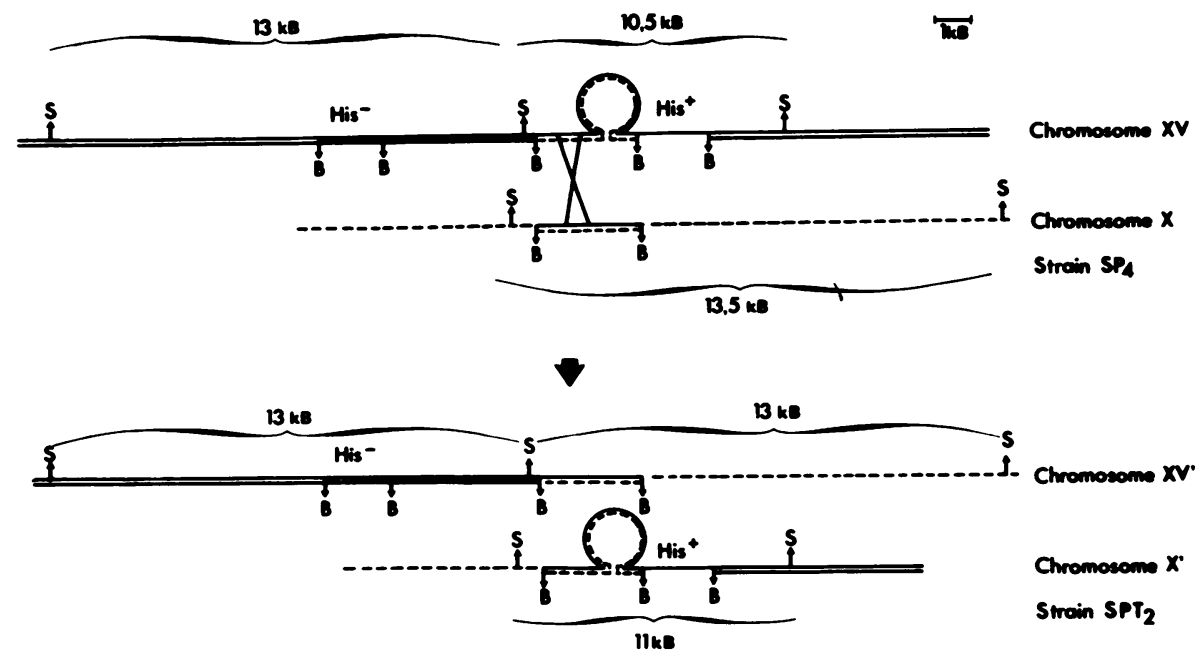

FIG. 11. Diagram of the sequence of events giving rise to a reciprocal translocation. B, BamHI; S, Sall. The Sall fragment sizes are only approximate. The pBR322 Sall site is the only one located with precision (19).

cloned and can be reinserted without inactivating an adjacent vital gene. This means generally that the cloned DNA fragment must contain at least one boundary between two genes but it is not necessary to have a selectable marker in the position where one wants to direct the translocation. The following is an operational outline. One plasmid bearing about the first two-thirds of an $X^{+}$gene, a full $Y^{+}$gene, and a piece of DNA of one of the chromosomal sites where the translocation is desired is inserted at this latter site by $Y^{+}$selection. A second plasmid bearing about the last two-thirds of $X^{+}$, a full $Z^{+}$gene, and a piece of DNA of the second chromosomal site chosen for the translocation is inserted at this site by $Z^{+}$phenotype selection. Then the selection of an $X^{+}$phenotype will allow recovery of the desired translocation. We note that ideally the $X^{-} Y^{-} Z^{-}$receptor strain should contain chromosomal deletions for the cloned fragments of $X, Y$, and $Z$, but this is not prerequisite for obtaining a reciprocal translocation as long as genetic and Southern blot analyses are carried out to eliminate recombination events other than those indicated in the outline.

This work confirms that it is possible to direct an interchromosomal rearrangement at chosen sites and suggests that the gross chromosomal organization of chromosomes $\mathrm{X}$ and XV must not be of particular importance for the cell's basic metabolism.

\section{ACKNOWLEDGMENTS}

We thank Jean-Luc Souciet and Jean-Claude Hubert for plasmids pJLS1 and BglB cloned in M13 mp7 phage and for critical comments on this work.

This research was supported by grants from Institut Nation- al de la Santé de la Recherche Médicale (ATP no. 72.79.104) and from the Fondation pour la Recherche Médicale.

\section{LTTERATURE CITED}

1. Cameron, J. R., E. Y. Loh, and R. W. Davis. 1979. Evidence for transposition of dispersed repetitive DNA families in yeast. Cell 16:739-751.

2. Chalef, D. T., and G. R. Fink. 1980 . Genetic events associated with an insertion mutation in yeast. Cell 21:227-237.

3. Chevallier, M. R., and M. Aigle. 1979. Qualitative detection of penicillinase produced by yeast strains carrying chimeric yeast-coli plasmids. FEBS Lett. 108:179-180.

4. Chevallier, M. R., J. C. Bloch, and F. Lecroute. 1980. Transcriptional and translational expression of a chimeric bacterial-yeast plasmid in yeast. Gene 11:11-19.

5. Clewell, D. B., and D. R. Helinskd. 1969. Supercoiled circular DNA-protein complex in Escherichia coli: purification and induced conversion to an open form. Proc. Natl. Acad. Sci. U.S.A. 62:1159-1166.

6. Cohen, S. N., A. C. Y. Chiang, and L. Hsu. 1972. Nonchromosomal antibiotic resistance in bacteria. Genetic transformation of $E$. coli by R factor DNA. Proc. Natl. Acad. Sci. U.S.A. 69:2110-2114.

7. Denis-Duphil, M., and J. G. Kaplan. 1976. Fine structure of the URA2 locus in Saccharomyces cerevisiae. II. Meiotic and mitotic mapping studies. Mol. Gen. Genet. 145:259-271.

8. Glansdorf, N. 1965. Topography of cotransductible arginine mutations in Escherichia coli K12. Genetics 51:167179.

9. Himnen, A., J. B. Hicks, and G. R. Fink. 1978. Transformation of yeast. Proc. Natl. Acad. Sci. U.S.A. 75:19291933.

10. Losson, R., and F. Lecroute. 1979. Interference of nonsense mutations with eukaryotic messenger RNA stability. Proc. Natl. Acad. Sci. U.S.A. 76:5134-5137.

11. Mortimer, R. K., and D. C. Hawthorne. 1966. Genetic mapping in Saccharomyces cerevisiae. Genetics 53:165173.

12. Rigby, P. W. G., M. Dieckmann, C. Rhodes, and P. Berg. 1977. Labelling deoxyribonucleic acid to high specific activity in vitro by nick translation with DNA polymerase I. J. Mol. Biol. 113:237-251.

13. Roeder, G. S., and G. R. Fink. 1980. DNA rearrangements 
associated with a transposable element in yeast. Cell 21:239-249.

14. Scherer, S., and R. W. Davis. 1979. Replacement of chromosome segments with altered DNA sequences constructed in vitro. Proc. Natl. Acad. Sci. U.S.A. 76:49514955.

15. Southern, E. M. 1975 . Detection of specific sequences among DNA fragments separated by gel electrophoresis. J. Mol. Biol. 98:503-517.

16. Struhl, K., J. R. Cameron, and R. W. Davis. 1976 Functional genetic expression of eukaryotic DNA in $E$. coli. Proc. Natl. Acad. Sci. U.S.A. 73:1471-1475.

17. Struhl, K., and R. W. Davis. 1980. A physical, genetic and transcriptional map of the cloned HIS3 gene region of Saccharomyces cerevisiae. J. Mol. Biol. 136:309-332.

18. Struhl, K., D. J. Stinchcomb, S. Scherer, and R. W. Davis. 1979. High frequency transformation of yeast: autonomous replication of hybrid DNA molecules. Proc. Natl. Acad. Sci. U.S.A. 76:1035-1039.

19. Sutclifie, J. G. 1978. pBR322 restriction map derived from the DNA sequence: accurate DNA size markers up to 4361 nucleotide pairs long. Nucleic Acids Res. 5:27212728.

20. Waldron, C., and F. Lacroute. 1975. Effect of growth rate on the amount of ribosomal and transfer ribonucleic acids in yeast. J. Bacteriol. 122:855-865. 